RELATO DE EXPERIÊNCIA

\title{
Problematizando a masculinidade hegemônica no ensino/treino do futebol: relato de um projeto socio-esportivo liderado por uma entidade estudantil
}

\author{
Problematizing hegemonic masculinity in soccer teaching / training: experience report in a \\ social project lead by a student entity \\ Luis Felipe Nogueira Silva, Gabriel Ferreira Santos, Nathalia Cristina Servadio, \\ Lucas Isamu Tamashiro, Alcides José Scaglia \\ Universidade Estadual de Campinas (Unicamp), Campinas, Brasil
}

\section{HISTÓRICO DO ARTIGO \\ Recebido: 20 abril 2021 \\ Revisado: 07 junho 2021 \\ Aprovado: 14 junho 2021}

\section{PALAVRAS-CHAVE:}

Masculinidade Hegemônica; Futebol; Pedagogia do Jogo.

\section{KEYWORDS:}

Hegemonic Masculinity; Soccer; Game's Pedagogy.

\section{RESUMO}

INTRODUÇÃO: As práticas esportivas são imbuídas por valores, crenças e concepções, que, se desprovidas de criticidade pedagógica, podem reforçar desigualdades de gênero, como as decorrentes da masculinidade hegemônica.

OBJETIVO: Relatar uma experiência educativa com vistas ao combate da masculinidade hegemônica no contexto esportivo, ancorada, teoricamente, pelo tripé de referenciais da Pedagogia do Esporte e a Pedagogia do Jogo.

MÉTODOS: O estudo está sustentado, metodologicamente, sustentado por uma perspectiva descritivoexploratória, por expor condutas pedagógicas decorrentes de aulas de futebol em um projeto social esportivo, conduzido por universitários e universitárias, na cidade de Limeira (SP).

RESULTADOS: A adoção de condutas didático-metodológicas, fundamentadas pela Pedagogia do Jogo, permitiram o desenvolvimento de conteúdos inerentes ao ensino e aprendizagem do futebol que, ao se distanciarem de concepções tradicionais de ensino, e dotadas de intencionalidades, fomentaram, também, problematizações e conscientizações sobre questões caras à justiça social, como a masculinidade hegemônica. CONCLUSÃO: Ao final do relato, foram articuladas, a partir dos baldrames pedagógicos que constituem a Pedagogia do Jogo, ações e intervenções que orientaram uma prática político-pedagógica contra hegemônica voltada ao esporte.

\section{ABSTRACT}

BACKGROUND: Sports practices are imbued with values, beliefs, and conceptions, which, devoid of pedagogical criticism, reinforce gender inequalities, such as those resulting from hegemonic masculinity.

OBJECTIVE: To report an educational experience with a view to combating hegemonic masculinity in the sporting context, theoretically anchored by the tripod of references in Sport Pedagogy and Game Pedagogy. METHODS: The study is supported, methodologically, by a descriptive-exploratory perspective, by exposing pedagogical behaviors resulting from soccer classes in a social sports project, conducted by university students, in the city of Limeira (SP, Brasil).

RESULTS: The adoption of didactic-methodological conducts, based on the Game's Pedagogy, allowed the development of contents inherent to the teaching and learning of football that, when distancing themselves from traditional teaching concepts, and endowed with intentionalities, also fostered problematizations and awareness of issues dear to social justice, such as hegemonic masculinity.

CONCLUSION: At the end of the report, actions and interventions from counter-hegemonic have politicalpedagogical practices been activated, allowed the pedagogical frameworks of Game's Pedagogy. 


\section{INTRODUÇÃO}

'No jogo, as máscaras caem. Se quiser conhecer uma pessoa, faça isso jogando'. A frase, cunhada pelo Prof. Alcides Scaglia para explicar o ato de jogar plenamente, denotado pelo estado de jogo, estado de absorção integral e envolvimento absoluto do indivíduo, caracteriza, para além da excitação propiciada pelo fenômeno jogo, irredutível, imprevisível, caótico e fascinante, a preservação da essência de quem joga, a despeito do estado de intensa imersão (FREIRE, 2002; SCAGLIA, 2011). Pelo bem e pelo mal.

Desse cair das máscaras, não é incomum que determinado sentimento de (re) afirmação insurja sobre indivíduos do gênero masculino na prática esportiva: o de mostrar ao resto do mundo o quanto são homens 'de verdade', tão 'machos' quanto seus pares. São impelidos a demonstrar um estereótipo de sujeito que reúne dado conjunto de habilidades motoras, comportamentos agressivos e características físicas que atestem virilidade (CORBIN; COURTINE; VIGARELLO, 2013). Essa postura viril no esporte abastece a estratégia hegemônica de educação e controle dos corpos, sintoma clarividente de uma categoria bastante específica de masculinidade: a hegemônica (CONNELL, 1996).

Cabe, primordialmente, ressaltar que o conceito de masculinidade não está imune aos processos de ressignificação relacio-nais e histórico-culturais, não sendo, portanto, estático e imutável. (CONNELL, 1995; KIMMELL; MESSNER, 1995; GARDINER, 2005; BOTTON, 2007). Isso porque a própria definição de "ser um homem" é inacabada e redefinida, a todo momento, por interações morais conjunturas econômicas, sociopolíticas e mecanismos de vigilância, das quais a própria masculinidade se articula pela dis-ciplinarização dos corpos intelectos (FOUCAULT, 2015; 2018). Prima, nas sociedades e culturas ocidentais, por naturalizar dife-renciações e classificações dos gêneros masculino e feminino como opostos extremos (VALE DE ALMEIDA, 1996; 2000).

Desse modo, a masculinidade hegemônica pressupõe uma espécie de domínio em relação a outras categorias de masculinidades, dentre as quais podemos inferir, com base em Connell (1995), a marginalizada, a subordinada e a cúmplice. Assim, indivíduos, ainda que exerçam um padrão de cis-heteronormatividade $^{1}$, por exemplo, mas não se encaixam em alguns moldes sociais, morais, físicos, mentais, étnicos, econômicos e comportamentais impostos pela hegemonia de gênero idealizada são excluídos e reprimidos tais como as mulheres e o público LGBTQ+, por não serem 'homens de verdade' (SEFFNER et al., 2013).

A masculinidade hegemônica comunga com preceitos que regem abordagens educacionais, galgadas no que Sousa Santos (2019) chama de epistemologias dominantes, ou, conforme Becker (2008) do senso comum, fortemente marcadas pelas teorias de aprendizagem racionalistas e liberais (inatista e empirista) (SILVA; LEONARDO; SCAGLIA, 2021). Nelas, práticas tradicionais encontram alicerces didático-metodológico para amplificar o conservadorismo pedagógico em espaços formativos, como os escolares, esportivos e religiosos, e manter valores caros ao status quo.

Ainda que não chancelem a masculinidade hegemônica de

${ }^{1}$ Seffner (2013) conceitua a heteronormatividade como norma que preza por naturalizar dada coerência entre sexualidade (macho/fêmea), gênero (tornar-se homem/mulher) e orientação sexua (homens possuem interesse afetivo em mulheres e vice-versa), que exclui, todas os indivíduos que não se reconheçam neste padrão binário, dicotômico e determinista. modo explícito, tais espaços são potencialmente nocivos ao seu combate por extinguirem e despolitizarem debates sobre a desigualdade de gênero e sexualidade, sofrida pelas mulheres (CONNELL, 1996; VALE DE ALMEIDA, 2000).

Connell (1996) destaca o papel que a atividade física e a prática esportiva, sobretudo no contexto da iniciação pela disciplinarização do corpo, exercem no processo de legitimação da masculinidade hegemônica ainda na infância, desvelando microfísicas de poder ${ }^{2}$ (FOUCAULT, 2018). No Brasil, preferir o voleibol ou a ginástica, tidas como 'atividades femininas' em detrimento ao futebol e o automobilismo, ou não denotar aptidões à performance física esperadas para um 'homem de verdade', pode significar uma ameaça à heteronormatividade, passível de retaliação social (CONNELL, 1995; 1996; MATOS, 2001; SANTOS, 2016).

A fuga de represálias se dá pela reprodução de discursos hegemônicos, que, uma vez internalizados e não repelidos, reforçam as alarmantes taxas de feminicídio e crimes contra travestis, homossexuais e transgêneros em âmbito nacional, bem como dificulta a inserção e nada contribui para combater altos índices de evasão destes indivíduos no ambiente esportivo (SAFFIOTI, 2015; SOARES; CHARLES; CERQUEIRA, 2019). Urge, portanto, a necessidade de que condutas pedagógicas voltadas ao esporte, para além de seu ensino, vivência e aprendizagem, estejam comprometidas também em rever valores que, implícita e explicitamente, estimulam a violência de gênero para confrontá-los, por meio de ações e intervenções contra-hegemônicas.

Nesse contexto, nosso objetivo foi relatar uma experiência pedagógica em aulas de futebol de um projeto social esportivo, descrevendo a influência da masculinidade hegemônica em um ambiente de iniciação esportiva e sua contraposição por treinadores e treinadoras, a partir da Pedagogia do Jogo.

\section{MÉTODOS}

O relato experiencial, pela qual prima o estudo, está assentado por uma abordagem metodológica qualitativa, de cunho descritivo-exploratório, uma vez que procurou reverberar e interpretar fatos passíveis de diálogo com o marco teórico, delineado na Introdução, e relacionar informações, a partir do contexto investigado, manifestadas por crenças, atitudes e fenômenos (MARCONI; LAKATOS, 2017).

Trata-se de um estudo de caso empírico que contou com observação participante, ao admitir participação direta dos autores, sendo eles e ela, inclusive, partes integrantes do estudo (MARCONI; LAKATOS, 2017). O estudo, assim, relata experiências pedagógicas, voltadas à problematização da masculinidade hegemônica em aulas de futebol, no contexto da iniciação esportiva, ocorridas entre agosto de 2018 e dezembro de 2019, na cidade de Limeira (SP).

Fundado em 2017 por iniciativa de estudantes de uma universidade pública local e apoiada por professores desta instituição, o projeto social esportivo atende, aproximadamente 100 adolescentes entre 10 e 15 anos - meninos, em sua grande maioria - de classe baixa, que residem em uma das zonas periféricas do supracitado município e estão devidamente matri-

Para Foucault (2018) o poder, ao contrário das propriedades, não está concentrado, nem extinguido em dimensões institucionais e lugares específicos, mas encontra-se diluído em 'microfísicas', redes instaveis de mecanismos e estratégias relacionais, mesmo periféricas, que afetam, através de
técnicas de dominação e disciplinarização, toda a estrutura social em maior ou menor instância de forma concreta. 
culados no ensino regular de escolas das redes municipal e estadual. Seu grande intento prima por aproximar a comunidade estudantil, formada majoritariamente por indivíduos de classe média e oriundos de outros municípios, com moradores e moradoras dos entornos da universidade, localizada em região de propensa vulnerabilidade socioeconômica. Além do futebol, o projeto social esportivo oferece aulas gratuitas de basquetebol, voleibol e tênis de mesa.

O quadro de professores e professoras do projeto social esportivo, ligados às aulas de futebol, era composto por cinco estudantes de graduação em Ciências do Esporte, supervisionados por profissionais de Educação Física - todos e todas voluntariamente. As aulas de futebol ocorreram em quadras de futebol de 7, popularmente conhecidas como 'society', em um clube poliesportivo na de Limeira (SP), que cedeu o espaço sem nenhuma contrapartida financeira. As turmas, divididas em duas categorias conforme faixa etária (sub-11 e sub-13), possuíam, ao todo, 50 alunos e alunas. Os materiais esportivos utilizados foram integralmente doados pelos próprios estudantes e supervisores do projeto.

Os dados foram obtidos a partir de relatos escritos tanto em diários de campo, que, a priori, compunham uma das estratégias de reflexão didático-metodológicas dos professores e professoras sobre suas próprias condutas pedagógicas, quanto provenientes de registros decorrentes reuniões quinzenais destes indivíduos para elaboração do planejamento de aulas (BOGDAN; BIKLEN, 1994).

\section{RESULTADOS E DISCUSSÃO}

A matriz curricular do projeto social esportivo, constituída em sua fundação, está balizada por três referenciais, que sustentam os processos de organização, sistematização, aplicação e avaliação da Pedagogia do Esporte, subcampo da Educação Física, que investiga a prática educativa no Esporte (PAES; MONTAGNER; FERREIRA, 2009): o técnico-tático, que sustenta ações de estratégias e compreensão de aspectos táticos ofensivos, defensivos e habilidades motoras gerais; o socioeducativo, ligado a valores, princípios e comportamentos humanizantes; e o histórico-cultural, que trata de promover o esporte, a partir da apreciação histórica e conhecimentos sobre eventos, regras e mídia (MACHADO; GALATTI; PAES, 2014; OLIVEIRA; SILVA; SCAGLIA, 2021).

\section{Contextualizando o desafio}

As aulas de futebol pressupunham a participação conjunta de meninos e meninas, além de serem conduzidas por professores voluntários de ambos os gêneros. A grande maioria dos adolescentes tinha, ali, seu primeiro contato com o ambiente de iniciação esportiva, embora já se conhecessem de outros contextos, como a convivência diária nas ruas dos bairros e nas escolas.

A configuração de turmas mistas, pouco usual em escolinhas de futebol no contexto brasileiro, permitiu aventar, rapidamente, condutas que caracterizam a masculinidade hegemônica entre os alunos. As turmas, tanto na categoria sub-11, quanto na categoria sub-13, eram compostas majoritariamente por meninos - em uma proporção de quatro para cinco indivíduos matriculados nas aulas da modalidade. Nenhum deles, até então, re- latou ter praticado futebol ou futsal com meninas nas aulas de educação física escolar - cenário aventado por Altmann (1998).

A Educação Física, sob uma perspectiva histórica, fundamentou muitos de seus conhecimentos pela conotação biológica, utilizando o sexo como principal componente para justificar capacidades físicas e habilidades de atletas e praticantes de esporte (LOURO; FELIPE; GOELLNER, 2010). Gaspari (2003), por outro lado, acentua que aulas de Educação Física com turmas mistas viabilizam aprendizados relacionados ao respeito, cooperação, solidariedade com o próximo, além de constituir um ambiente potencialmente favorável à discussão de questões associadas à identidade de gênero (LOURO, 2014).

As aulas, que ocorriam duas vezes por semana, tinham duração média de 75 minutos e se desenvolviam da seguinte maneira: nos 10 primeiros minutos, alunos e alunas brincavam e interagiam livremente pela quadra, sem intervenções dos professores, com os materiais disponíveis - bolas, coletes e cones. Em seguida, era realizada uma roda conversa introdutória, com a problematização de valores caros à convivência social humanizante, baseados em questões sociais em evidência naquele dia ou naquela semana, presumidos pelo referencial socioeducativo da Pedagogia do Esporte e apresentação dos conteúdos a serem desenvolvidos, em consonância não apenas ao que rege o referencial técnico-tático, sustentadas pelo processo organizacional sistêmico da Pedagogia do Jogo (SCAGLIA, 2013; 2017; 2020).

Caracterizada por Scaglia et al. (2020) como abordagem pedagógica que sustenta propostas didático-metodológicas progressistas ao ensino de esportes, a Pedagogia do Jogo busca aliar a essência subversiva e imanente do jogo providas de condutas emancipatórias e humanizantes. Prega o rompimento paradigmático nos ambientes educacionais pelo interacionismo pedagógico que enxerga o conhecimento não como mero instrumento técnico, excludente e transmitido unilateralmente, e, sim, concebido a partir das interações entre indivíduos e deles com o mundo (SILVA; LEONARDO; SCAGLIA, 2021).

De acordo com Scaglia et al. (2020), as bases epistemológicas da Pedagogia do Jogo estão fundadas pelo encadeamento entre as teorias sistêmica (MORIN, 2015), histórico-cultural (FREIRE, 1979; 2016; 2017; 2018) e a 'pedagogia da rua', aludida por Freire (2011). Esta última, conclama o ensino-aprendizagem do futebol a partir de brincadeiras de bola com os pés em ambientes informais, como a rua, sustentadas por quatro princípios basilares (Quadro 1).

Quadro 1. Princípios pedagógicos para o ensino do futebol.

\begin{tabular}{|ll|}
\hline Princípios Pedagógicos & Objetivos \\
\hline $\begin{array}{l}\text { Ensinar futebol a todos e } \\
\text { todas }\end{array}$ & $\begin{array}{l}\text { A ação pedagógica deve assegurar que todas as pessoas } \\
\text { possuam os mesmos direitos de aprender a jogar futebol, } \\
\text { independente do gênero, classe social ou etnia. }\end{array}$ \\
\hline $\begin{array}{l}\text { Ensinar bem futebol a todos } \\
\text { e todas }\end{array}$ & $\begin{array}{l}\text { A ação pedagógica tem o compromisso de fazer com que todas } \\
\text { as pessoas evoluam e aprimorem suas habilidades no futebol. }\end{array}$ \\
\hline $\begin{array}{l}\text { Ensinar mais que futebol a } \\
\text { todos e todas }\end{array}$ & $\begin{array}{l}\text { A ação pedagógica deve permitir que todas as pessoas possu- } \\
\text { am aprendizagens relacionadas não apenas aos conteúdos do } \\
\text { jogo de futebol, mas, também, sobre valores sociais, morais } \\
\text { e culturais. }\end{array}$ \\
\hline $\begin{array}{l}\text { Ensinar a todos e todas } \\
\text { gostarem de esporte }\end{array}$ & $\begin{array}{l}\text { A ação pedagógica deve reforçar o estímulo para que todas as } \\
\text { pessoas apreciem a prática esportiva, a ponto de carrega-la } \\
\text { por toda a vida. }\end{array}$ \\
\hline
\end{tabular}

Adaptado de Freire (2011). 
Assim, as atividades se desenvolviam a partir das matrizes de jogos, evocadas por Scaglia (2013; 2014): primeiro, eram desenvolvidos jogos conceituais, em que as referências estruturais (colegas de equipe, rivais, bola, alvo, espaço de jogo e regras estruturais) e as referências funcionais (princípios operacionais ofensivos e defensivos e regras funcionais) não respeitam a lógica do jogo formal de futebol, como ocorre, por exemplo, no popular 'bobinho'; em seguida, jogos conceituais em ambiente específico, em que as referências estruturais do jogo formal são respeitadas, mas as referências funcionais não, a exemplo do que acontece no jogo tradicional 'gol caixote'; e, por fim, o jogo formal, o 'coletivo'. As aulas eram encerradas com uma roda de conversa final, recordando os conteúdos técnico-táticos trabaIhados, bem como suas intencionalidades, e problematizando condutas eventualmente problemáticas dos alunos e que confrontaram os valores inicialmente propostos.

Durante as rodas de conversas finais, foram recorrentes, nos três primeiros meses de aulas, questionamentos e reflexões quanto ao preconceito afirmado pelos meninos às meninas. Reclamações, xingamentos e expressões que inferiorizavam as alunas eram comuns. Além disso, era possível notar certo boicote durante as atividades: muitos deles evitavam, ao máximo, passar a bola a elas. 0 menino que não era bem sucedido em alguma ação técnico-tática sobre uma menina, virava alvo de zombaria 'Fulana é melhor que você', gritavam e gargalhavam os demais. Havia uma espécie de hierarquia velada: além das meninas, meninos tidos com menos habilidosos eram ignorados no jogo e na própria interação pelos mais populares da turma.

A violência verbal, moral e simbólica destilada pelos meninos, de modo explícito, não tardou a impactar no quórum de meninas: a evasão durante o primeiro trimestre de aulas foi tamanha que a educação mista, acabou descaracterizada. Ao final do período, dinâmicas como 'caça ao tesouro' e teatros pedagógicos foram promovidos para problematizar as repressões e conscientizar os alunos de seus malefícios - não apenas internos, mas sociais. Por fim, no processo de feedback estimulado pelo projeto social-esportivo, na qual os alunos e alunas escreveram cartas para relatar o que mais e o que menos gostaram das aulas, as poucas meninas restantes descreveram, de forma unânime, incômodo com a agressividade masculina.

\section{A inserção do diálogo problematizador}

Para Connell (1996), a masculinidade hegemônica está imbrincada em práticas institucionais, também na Educação Física, espaço em que a reprodução da ordem de gênero e celebração de uma masculinidade bem específica por muito tempo pouco foram discutidas. Griffin (1989) cita que, por este motivo, quando um menino é comparado com uma menina ou perde para uma durante uma prática esportiva, atesta o golpe de que seu 'orgulho masculino' acaba profundamente atingido e ofendido. A Educação Física e o ambiente esportivo são costumeiramente pouco acolhedores e receptivos às mulheres e meninos e homens, inibidos e desmotivados em função da pressão causada para atender comportamentos viris, por práticas pedagógicas que referenciam padrões corporais e gestos técnicos estereotipados (SILVA; BOTELHO-GOMES; GOELLNER, 2008; VIANA; ALTMANN, 2013).

A popularidade dos meninos era definida, para além das ha- bilidades com a bola, pela agressividade física, verbal e comportamentos hostis, maquilhados como desafiadores e inerentes aos indivíduos de 'personalidade forte'. Quando perguntados sobre os motivos que levavam a essas posturas, os meninos respondiam com frases como 'na minha escola é assim' ou 'é o que acontece sempre', 'menina não tem o dom para jogar', evidência de que as condutas que transbordam virilidade, como controle e símbolo de força moderna, repulsam o frágil e, portanto, servis à masculinidade hegemônica estavam, neles, interiorizadas (ALTMANN, 1998; CORBI; COURDINE; VIGARELLO, 2013).

Louro (2014) salienta que o processo de genderização na Educação Física e no esporte ocorre em discursos, saberes e práticas sociais que assombram, além da musculatura dos corpos, gestos padrões e equipamentos esportivos. Para Felipe (2007), esses componentes marcam, distinguem e segregam corpos e seus significados, atribuídos ao que deve ser masculino e ao que deve ser feminino, utilizados para justificar a participação de homens e mulheres em diferentes modalidades esportivas.

O desafio nas aulas, assim, passava por transcender os impactos da problematização da masculinidade hegemônica em aula. Ainda que algumas atitudes fossem repreendidas no ambiente pedagógico, o comportamento hegemônico parecia, segundo relatos dos próprios meninos, condição sine qua non para que pudessem se inserir em círculos sociais, nas escolas, na rua, no bairro e até entre familiares.

As rodas de conversas iniciais durante as aulas passaram, então, a abordar, a partir do diálogo, questões referentes à identidade de gênero e a necessidade em respeitá-las para uma convivência social mais justa. Temas relacionados ao futebol de mulheres - em especial à edição 2019 da Copa do Mundo FIFA Feminina - explorados pela mídia, eram evocados e articulados com situações problemáticas identificadas em aulas anteriores que materializassem a masculinidade hegemônica.

Os diálogos procuravam enfatizar que meninos e meninas, naquele contexto, possuíam a mesma paixão pelo futebol e igual capacidade em alcançar um estágio de arrebatamento capaz de suspender, momentaneamente, a realidade, pela entrega total e concentração absoluta ao jogo (SCAGLIA, 2011). A isonomia comportamental dos meninos às meninas, antes restrita aos menos habilidosos - também excluídos pela masculinidade hegemônica - passou a também ser praticada pelos 'líderes' das turmas. Para tanto, as rodas de conversas finais das aulas, momentos em que todos e todas tinham espaço de abertura para contarem o que sentiam em relação as atividades desenvolvidas, pareceram decisivas. Neste momento, as alunas e os alunos, que não compunham o círculo de influência dos líderes, ganhavam voz e recebiam atenção, costumeiramente minimizada no decorrer das aulas.

A fala de meninas e meninos oportunizavam, desse modo, debates e reflexões sobre pautas caras à igualdade e respeito mútuo entre seres humanos, dentro e fora do projeto. As conversas, mediadas pelos treinadores e treinadoras, procuravam estabelecer um tom de intervenção de não-diretividade, buscando, a partir de exemplos que rondavam o cotidiano social e familiar de cada um deles e delas e que estivessem para além do contexto esportivo. Ainda que as falas carreguem estereótipos hegemônicos, decorrentes de outros espaços institucionais (CONNELL, 1996), Freire (2002) frisa que, mais do que não reforçá-los, é preciso combatê-los para evitar o sentimento social 
de conformidade a partir de processos educacionais que primem pela conscientização coletiva (FREIRE, 1979; 2016; 2018; HOOKS, 2017).

Depois do primeiro semestre de aulas, algumas condutas pedagógicas dos treinadores e treinadoras foram revisadas. Jogos com regras que obrigavam que a bola passasse por todos os jogadores e jogadoras da equipe para que o gol fosse validado foram, aos poucos, perdendo espaço. Primeiro, porque sofriam deturpação em certas ocasiões - as meninas eram 'obrigadas' a se posicionarem ao lado de uma das traves e tinham a missão de apenas empurrarem a bola ao alvo, como modo de não 'atrapalharem' o jogo e terem ínfima participação ativa na construção das jogadas. Ademais, esse tipo de procedimento, típico do behaviorismo pedagógico, ao condicionar e impor padrões de comportamentos pouco contribuía ao desenvolvimento da autonomia de jogadores e jogadoras, estando, assim, em dissonância aos princípios didático-metodológicos da Pedagogia do Jogo.

Palavras de encorajamento e atribuição de responsabilidades como assumir o papel de capitã de sua equipe ou cobradora oficial de faltas ou pênaltis passaram a ditar as ações e intervenções pedagógicas durante as atividades nas aulas. As alunas começaram a se sentir empoderadas para cobrar posturas, dentro do jogo, que respeitassem seus direitos em jogar futebol e combatessem o que Freire (2018) chama de 'cultura do silêncio', a que estiveram, até então, apregoadas. Apesar da dificuldade inicial, atitudes intrínsecas à masculinidade hegemônica foram, aos poucos, limadas. Os 'líderes' da turma, embora não perdessem a influência sobre os demais colegas, soavam consideravelmente menos propensos à agressividade verbal. Não obstante, a inserção social e técnico-tática de meninas e meninos menos habilidosos passou a acontecer de forma natural.

\section{Por uma Pedagogia do Esporte contra-hegemônica}

Respeito, igualdade, fraternidade e solidariedade, valores designados a partir do referencial socioeducativo da Pedagogia do Esporte, um dos baldrames curriculares do projeto, se encadearam às problematizações quanto à masculinidade hegemônica entre os alunos. Ao fim do primeiro ano de aulas, a presença das meninas foi naturalizada, a ponto de haver repreensão dos próprios meninos, quando alguma delas, sobretudo as recém-chegadas, pareciam pouco ativas no jogo - algo impensável em meses anteriores. Mostra de que o ensino conscientizador e problematizador de gêneros através da pratica esportiva, uma vez planejado, organizado e sistematizado (com margem à eventuais rearranjos didáticos) e que expurgam a fragmentação e o imediatismo, trazem resultados frutíferos.

Hooks (2017) reforça o papel crucial do fazer pedagógico comprometido com práticas de inclusão e superação de discursos e práticas hegemônicas na Educação Física e atividades esportivas. Nesse sentido, o empenho de treinadores e treinadoras nas aulas de futebol do projeto socio-esportivo para articular estratégias, a partir do contexto esportivo, para materializar as intencionalidades aventadas pela Pedagogia do Jogo e seu propósito de humanização crítica dos processos pedagógicos, engajada em lutas sociais, merece notoriedade.

A Pedagogia do Jogo não se resume ao jogo, propriamente dito, enquanto atividade física e motora e suas infinitas possibilidades e potencialidades, tampouco, ao 'lúdico'. Está, sim, comprometida com os preceitos da Pedagogia do Esporte, conceituados por Paes; Montagner; Ferreira (2009) e os princípios pedagógicos evocados por Freire (2011) no Quadro 1, em especial o segundo deles - 'ensinar mais que futebol' - por alinhar em seus desígnios, o conceito de práxis: sua prática está alicerçada por uma ou mais teorias imbuídas de intencionalidades que confrontem o que Freire (2018) chama de educação bancária, seja em seu formato tradicional ou por roupagens neoliberais, dotadas de positividade, que almejam o desenvolvimento de competências, habilidades e 'protagonismos' por processos educacionais ativos, contudo, de parco aprofundamento crítico.

A problematização da masculinidade hegemônica, por parte dos treinadores e treinadoras, se deu, evidentemente, pelo reconhecimento das microfísicas de poder, no contexto a que estavam inseridos, sem que abrissem mão, contudo, da dialogicidade e do o almejar o inédito-viável para transformar dada realidade (FREIRE, 2016; 2017; 2018; HOOKS, 2017; FOUCAULT, 2018). Nesse sentido, Louro (2014) ressalta que a produção de desigualdade de gênero, força propulsora da masculinidade hegemônica, não se resume às relações interpessoais, sendo tecidas, principalmente, por redes complexas e violências implícitas de poder, que instituem estratégias de hierarquias institucionais, discursivas, simbólicas e práticas entre os gêneros.

Mais do que aprender a jogar futebol, alunos e alunas do projeto foram expostos à uma espécie de transgressão educacional pelo diálogo esperançante e conscientizador - não o anti-diálogo, baseado na crítica contundente e destrutiva, que coisifica relações e, portanto, desprovida de propósitos humanizantes, características do ativismo raso - mas à comunicação horizontal e afetuosa: suas contradições, ao invés de salvaguardarem atitudes odientas e revanchistas, foram acolhidas pelos treinadores e treinadoras, entendidas como produtos de uma educação institucional opressora, alicerçada por epistemologias dominantes e hegemônicas, que, por sua vez, validam práticas e relações incitadoras de gestos, modos de ser, estar e ler o mundo que sustentam relações de poder entre os gêneros (; FREIRE, 2016; 2018; HOOKS, 2017; ).

Isto posto, o relato expõe que os processos educacionais no âmbito esportivo são, sim, permeáveis ao olhar social crítico e problematizador, insuflados pela Pedagogia do Jogo. Além da autonomia cognitiva, gerada pela condução de jogos e brincadeiras tradicionais de bola com os pés sob um viés sistêmico, que fomentem tomadas de decisão capazes de resolver as inúmeras problemáticas emergidas do jogo, a Pedagogia do Jogo está atenta à promoção da autonomia moral: prega a autoformação e conscientização dos indivíduos, inacabáveis, sobre as opressões advindas não apenas dos sistemas institucionais, regidos pelas classes dominantes e colonialistas, mas das relações de poder implícitas nas teias sociais (FREIRE, 1979; 2016; 2017; 2018; HOOKS, 2017; FOUCAULT, 2018). Ao lerem o mundo criticamente, compreenderem seu lugar nele como produtores de cultura, esses mesmos indivíduos, ao invés da vingança, buscam justiça: se libertam, enfim, do desejo de ocupar o lugar de seus algozes como ex-oprimidos opressores e subvertem o fatalismo alienante. 
Problematizando a masculinidade hegemônica no ensino/treino do futebol: relato de um projeto socio-esportivo liderado por uma entidade estudantil

\section{CONCLUSÃO}

A Pedagogia, compreendida como ciência da prática educativa, é responsável por articular métodos e didáticas dotados de intencionalidades, que, preferencialmente, façam com que os indivíduos pensem, sintam e ajam melhor e de forma consciente. Assim, treinadores e treinadoras são, a priori, pedagogos e pedagogas do esporte, haja vista sua enorme responsabilidade nos processos formativos de seres humanos e gestão de valores sociais, éticos e morais, para além das competências técnicas, táticas cognitivas e físicas.

Pedagogos e pedagogas do esporte têm, portanto, o dever de combater, diariamente, preconceitos, discriminações e exclusão de indivíduos, posturas que marcam a opressão social e são aventadas, dentre outros inúmeros fatores, pela masculinidade hegemônica, potencializada, ainda mais, em âmbito esportivo. Os relatos sobre aulas de futebol em um projeto social esportivo voltado à adolescentes de classes sociais menos favorecidas, exemplificam que o esporte é palco, também, para posturas educacionais críticas, que não se restrinjam aos saberes e habilidades do jogo, como defende a Pedagogia do Jogo, abordagem pedagógica que insurge da confluência de concepções sistêmicas/complexas, histórico-culturais e construtivistas da educação.

A conscientização sobre a masculinidade hegemônica entre meninos e meninas permitiu transformar um ambiente, marcado por espelhar opressões socais, como a de gênero. A experiência reforça a conotação processual no tensionamento de estruturas solidificadas pelo inconsciente coletivo. Mudanças não ocorrem de um dia para o outro, afinal. O diálogo afetuoso, fraternal e capaz de reconhecer, empaticamente, as contradições do outro, preceitos orquestrados pelo Prof. Paulo Freire, patrono da educação brasileira, não apenas cabem no ambiente esportivo, impregnado pelo positivismo performático, como são necessários à humanização das relações no ensino, aprendizagem e treinamento nestes contextos.

\section{REFERÊNCIAS}

ALTMANN, H. Rompendo fronteiras de gênero: Marias (e) homens da Educação Física. 1998. 111f. Dissertação (Mestrado em Educação) - Universidade Federal de Minas Gerais, Belo Horizonte, 1998.

BECKER, F. Aprendizagem - concepções contraditórias. Revista Eletrônica de Psicologia e Epistemologia Genética, Marília, v. 1, n. 1, p. 53-73, 2008

BOGDAN, R. C.; BIKLEN, S. K. Investigação qualitativa em educação: uma introdução a teoria e aos métodos. Porto: Porto Editora, 1994.

BOTTON, F. B. A masculinidade em questão: uma perspectiva de construção teórica. Vernáculo, Curitiba, n. 19 e 20, p. 109-20, 2007.

CONNELL, R. W. Masculinities: Knowledge, power and social change. Los Angeles: University of California Press, 1995

CONNELL, R. W. Teaching the boys: New research on masculinity, and gender strategies for schools. Harvard Educational Review, Nova lorque, v. 98, p. 206-235, 1996.

CORBIN, A.; COURDINE, J. J.; VIGARELLO, G. História da virilidade. Petrópolis: Vozes, 2013.

FELIPE, J. Gênero, sexualidade e a produção de pesquisas no campo da educação: possibilidades, limites e a formulação de políticas públicas. Pro-Posições, Campinas, v. 18, n. 2, n. 53, p. 77-87, 2007.

FOUCAULT, M. História da sexualidade. 3. ed. Rio de Janeiro: Paz \& Terra, 2015.

FOUCAULT, M. Microfísica do poder. 7. ed. Rio de Janeiro: Paz \& Terra, 2018.
FREIRE, J. B. S. Educação física de corpo inteiro: teoria e prática da educação física. 4. ed. São Paulo: Scipione, 2002.

FREIRE, J. B. S. Pedagogia do futebol. 3. ed. São Paulo: Autores Associados, 2011.

FREIRE, P. Conscientização: teoria e prática da libertação. São Paulo: Cortez \& Moraes, 1979.

FREIRE, P. Pedagogia da autonomia: saberes necessários à prática educativa. 55. ed. Rio de Janeiro: Paz e Terra, 2017.

FREIRE, P. Pedagogia da esperança: um reencontro com a pedagogia do oprimido. 23. ed. Rio de Janeiro: Paz e Terra, 2016.

FREIRE, P. Pedagogia do oprimido. 66. ed. Rio de Janeiro: Paz e Terra, 2018. GARDINER, J. K. Men, masculinities, and feminist theory. In: KIMMEL, M. S. HEARN, J.; CONNELL, R. W. (Eds.). Handbook of studies on men and masculinities. Thousand Oaks: Sage Publications, 2005. p. 35-50.

GASPARI, T. C. Possibilidades da Educação Física na escola: ouvindo os professores. Niterói. In: VII Encontro Fluminense de Educação Física Escolar. Anais... Universidade Federal Fluminense, p. 233-237, 2003.

GRIFFIN, P. Gender as a socializing agent in physical education. In: SCHEMPP, T. J. T. P. G. (Ed.). Socialization into physical educational: learning to teach. Indianapolis: Benchmark, 1989. p. 219-234.

HOOKS. B. Ensinando a transgredir: a educação como prática da liberdade [trad. Marcelo Brandão Cipolla. 2. ed. São Paulo: WMF Martins Fontes, 2017.

KIMMELL, M. S.; MESSNER, M. Men's lives. 3. ed. Boston: Allyn \& Bacon, 1995.

LOURO, G. L. Gênero, sexualidade e educação: uma perspectiva pós-estruturalista. 16. ed. Petrópolis: Vozes, 2014.

LOURO, G. L.; FELIPE, J.; GOELLNER, S. V. Corpo, gênero e sexualidade: um debate contemporâneo na educação. 5. ed. Petrópolis: Vozes, 2010.

MACHADO, G. V.; GALATTI, L. R.; PAES, R. R. Pedagogia do esporte e o referencial histórico-cultural: interlocução entre teoria e prática. Pensar a Prática, Goiânia, v. 17, n. 2, p. 414-30, 2014.

MARCONI, M. A.; LAKATOS, E. M. Fundamentos de metodologia científica. 8. ed. São Paulo: Atlas, 2017.

MATOS, M. I. S. de. Por uma história das sensibilidades - a masculinidade. História: Questões \& Debates, Curitiba, n. 34, p. 45-63, 2001.

MORIN, E. Introdução ao pensamento complexo. 5. ed. Rio de Janeiro: Sulina, 2015.

OLIVEIRA, M. F.; SILVA, L. F. N.; SCAGLIA, A. J. Pedagogia do esporte: percepções sobre as implicações práticas de um projeto social esportivo no contexto universitário. Corpoconsciência, Cuiabá, v. 25, n. 1, p. 23-38, 2021.

PAES, R. R.; MONTAGNER, P. C.; FERREIRA, H. B. Pedagogia do esporte: iniciação e treinamento em basquetebol. Rio de Janeiro: Guanabara Koogan, 2009.

SAFFIOTI, H. I. B. Gênero, patriarcado e violência. 2. ed. São Paulo: Expressão Popular, 2015.

SANTOS, F. B.; POSTINGUEL, D. Masculino plural e comunicação publicitária: a dinâmica atualização da masculinidade hegemônica. Novos Olhares, São Paulo, v. 5, n. 1, p. 79-89, 2016.

SCAGLIA, A. J. O futebol e as brincadeiras de bola: a família dos jogos de bola com os pés. São Paulo: Phorte, 2011.

SCAGLIA, A. J. Pedagogia do jogo: o processo organizacional dos jogos esportivos coletivos enquanto modelo metodológico para o ensino. Revista Portuguesa de Ciências do Desporto, Porto, v. 17, S1.A, p. 27-38, 2017.

SCAGLIA, A. J.; PEREIRA, A. S.; REIS, F. P. G.; CARNEIRO, K. T. Pedagogia das lutas/artes marciais: do ambiente de jogo à sistematização do ensino. Curitiba: Brasil Publishing, 2021.

SCAGLIA, A J.: REVERDITO, R. S.; LEONARDO, L.; LIZANA, C. J. R. O ensino dos jogos esportivos coletivos: as competências essenciais e a lógica do jogo em meio ao processo organizacional sistêmico. Movimento, Porto Alegre, v. 19, n. 4, p. 227-49, 2013.

SEFFNER, F. Sigam-me os bons: apuros e aflições nos enfrentamentos ao regime da heteronormatividade no espaço escolar. Educação e Pesquisa, São Paulo, v. 39, n. 1, p. 145-59, 2013.

SILVA, L. F. N.; LEONARDO, L.; SCAGLIA, A. S. Epistemologia da prática pedagógica na educação física e esporte: mapeamento a partir de um instrumento metodológico. Lecturas: Educación Fisica y Deportes, Buenos 
Aires, Revista Digital, v. 25, n. 274, p. 145-63, 2021. Disponível em: <https://www.efdeportes.com/efdeportes/index.php/EFDeportes/article/ view/2344/1365>. Acessado em: 15 de janeiro de 2021.

SILVA, P.; BOTELHO-GOMES, P.; GOELLNER, S. V. Educação física no sistema educativo português: um espaço de reafirmação da masculinidade hegemônica. Revista Brasileira de Educação Física e Esporte, São Paulo, v. 22, n. 3 , p. 219-33, 2008.

SOARES, D. Z.; CHARLES, C.; CERQUEIRA, C. C. A. X. Feminicídio no Brasil: gênero de quem mata e quem morre. In: XIII Encontro Nacional de Pós-Graduação e Pesquisa em Geografia, 2019. Anais... São Paulo, 2019.
SOUSA SANTOS, B. O fim do império cognitivo: a afirmação das epistemologias do Sul. São Paulo: Autêntica, 2019. [e-book]

VALE DE ALMEIDA, M. Corpo presente: treze reflexões antropológicas do corpo. Oeiras: Celta, 1996.

VALE DE ALMEIDA, M. Senhores de si: uma interpretação antropológica da masculinidade. Lisboa: Edição Fim de Século, 2000.

VIANA, A. E. S.; ALTMANN, H. Meninas e meninos em campo: experiência com o jogo em uma escola de futebol. Revista Mineira de Educação Física, Viçosa, v. 23, n. 1, p. 113-22, 2015.

\section{CONFLITO DE INTERESSE}

Os autores do estudo declaram não haver conflito de interesses

\section{FINANCIAMENTO}

Este estudo não teve apoio financeiro.

\section{ORCID E E-MAIL DOS AUTORES}

Luis Felipe Nogueira Silva (Autor Correspondente)

ORCID: 0000-0003-0583-4445.

E-mail: luisfelipenogu@gmail.com

Gabriel Ferreira Santos

ORCID: 0000-0002-3173-8302.

E-mail: gabrielsccp7@hotmail.com

Nathalia Cristina Servadio

ORCID: 0000-0002-8947-0433.

E-mail: nathaliaservadio@gmail.com

Lucas Isamu Tamashiro

ORCID: 0000-0002-8790-4576.

E-mail: lucastamashiro7@gmail.com

Alcides José Scaglia

ORCID: 0000-0003-1462-1783.

E-mail: alcides.scaglia@gmail.com 